\title{
Premaxillary crest variation within the Wukongopteridae (Reptilia, Pterosauria) and comments on cranial structures in pterosaurs
}

\author{
XIN CHENG ${ }^{1,2}$, SHUNXING JIANG $^{1}$, XIAOLIN WANG ${ }^{1,3}$ and ALEXANDER W.A. KELLNER ${ }^{2}$ \\ ${ }^{1}$ Key Laboratory of Vertebrate Evolution and Human Origins of Chinese Academy of Sciences, Institute of Vertebrate \\ Paleontology and Paleoanthropology, Chinese Academy of Sciences, P.O. Box 643, 100044, Beijing, China \\ ${ }^{2}$ Laboratory of Systematics and Taphonomy of Fossil Vertebrates, Department of Geology and Paleontology, Museu Nacional/ \\ Universidade Federal do Rio de Janeiro, Quinta da Boa Vista, s/n, São Cristóvão, 20940-040 Rio de Janeiro, RJ, Brazil \\ ${ }^{3}$ University of Chinese Academy of Sciences, 100049, Beijing, China
}

Manuscript received on October 28, 2016; accepted for publication on January 9, 2017

\begin{abstract}
Cranial crests show considerable variation within the Pterosauria, a group of flying reptiles that developed powered flight. This includes the Wukongopteridae, a clade of non-pterodactyloids, where the presence or absence of such head structures, allied with variation in the pelvic canal, have been regarded as evidence for sexual dimorphism. Here we discuss the cranial crest variation within wukongopterids and briefly report on a new specimen (IVPP V 17957). We also show that there is no significant variation in the anatomy of the pelvis of crested and crestless specimens. We further revisit the discussion regarding the function of cranial structures in pterosaurs and argue that they cannot be dismissed a priori as a valuable tool for species recognition.
\end{abstract}

Key words: Wukongopteridae, Pterosauria, cranial crest, sexual dimorphism, China.

\section{INTRODUCTION}

Cranial crests are present in nearly all pterosaur groups, from species found in Triassic deposits (e.g., Dalla Vecchia 2014) to the last taxa recorded from Late Cretaceous strata (e.g., Kellner and Langston 1996). The various cranial crests have been widely used for taxonomic purposes (e.g., Wellnhofer 1991, Kellner 2003, Andres et al. 2014) and there are several bones involved in those structures, such as the premaxillae, frontals, parietals, supraoccipital (e.g., Young 1964, Campos and Kellner 1985, Kellner and Campos 2002a,

Correspondence to: Xiaolin Wang

E-mail: wangxiaolin@ivpp.ac.cn
Wang and Zhou 2003, Wang et al. 2012, 2014a), and the dentaries (e.g., Wellnhofer 1987, Kellner et al. 2013, Wang et al. 2014b). Cranial crests are more frequent in pterodactyloid pterosaurs, but some are found also in non-pterodactyloids (Czerkas and Ji 2002, Dalla Vecchia 2009, Stecher 2008).

Most recently several specimens of the nonpterodactyloid clade Wukongopteridae were discovered in Middle to Late Jurassic Tiaojishan Formation in China (Zhou and Wang 2010, Sullivan et al. 2014). These specimens have called attention due to the particular array of primitive and derived features that placed them as closely related to the derived Pterodactyloidea, although their actual phylogenetical position is still disputed (Wang et 
al. 2009, 2010, Lü et al. 2010, Andres et al. 2014). There is also some discussion about their diversity, with some authors considering them monospecific (Lü et al. 2010, 2011a) while others regard them as more diverse (Wang et al. 2010, Lü et al. 2011b).

Among the anatomical features used to establish the wukongopterid diversity is the premaxillary crest. In some specimens, the crest is absent (Wang et al. 2010, Lü et al. 2011a) while in others it varies in shape and extension (Wang et al. 2010, Lü et al. 2011b, Cheng et al. 2016). More recently, a specimen with an associated egg, that lacked a crest, was reported (Lü et al. 2011a), raising the possibility that the presence and absence of such structure might indicate sexual dimorphism in pterosaurs.

The main purpose of this paper is to review and discuss the differences of the cranial crests found in the Wukongopteridae and revisit the debate concerning these head structures. We also briefly report on a new wukongopterid specimen (IVPP V 17957) that shows a premaxillary crest different from all others within this group.

Institutional Abbreviations: HGM-Henan Geological Museum, Zhengzhou, Henan Province, China; IVPP-Institute of Vertebrate Paleontology and Paleoanthropology, Chinese Academy of Sciences, Beijing, China; YH-Yizhou Museum, Yixian, Liaoning Province, China; ZMNHZhejiang Museum of Natural History, Hangzhou, Zhejiang Province, China

\section{DESCRIPTION AND COMPARISONS}

Up to now, eight specimens referable to the Wukongopteridae have been published, all coming from the Middle to Upper Jurassic Tiaojishan Formation (northeast China). They have been considered to represent three genera, Wukongopterus, Darwinopterus, and Kunpengopterus (Wang et al. 2009, 2010, 2015, Lü et al. 2010, 2011a, b), or remained indeterminate (Cheng et al. 2016). Two additional individuals were also referred to this clade. One is the holotype of Changchengopterus pani, that lacks a skull (Lü 2009) and has been considered a putative wukongopterid (Wang et al. 2009). However, this very small and apparently ontogenetic young animal has comparatively shorter cervical vertebrae compared to other wukongopterids and therefore its exact phylogenetical position remains to be established. The second specimen was described by Zhou and Schoch (2011) and consists of a fairly complete skeleton lacking the skull. Based on the elongation of the cervical vertebrae, along with a long tail and developed fifth toe, it can confidently be assigned to the Wukongopteridae.

Recently, a new specimen (IVPP V 17957) was discovered from the same region and horizon as the holotypes of Wukongopterus, Kunpengopterus and Darwinopterus (Wang et al. 2009, 2010, Lü et al. 2010, 2011b). IVPP V 17957 consists of a partial skeleton with incomplete skull that can be regarded as a wukongopterid pterosaur based on the following characters: confluent nasoantorbital fenestra, quadrate inclined backwards, elongated cervical vertebrae, reduced cervical ribs, length of the wing metacarpal about half the length of the first wing phalange, elongated tail enclosed by rod-like bony extensions made by the zygapophyses. This new specimen shows a premaxillary crest that differs from previous wukongopterids and therefore is included in the present paper. A full description of this material will be done elsewhere.

All wukongopterid specimens with complete skull can be divided into two main types, either having or lacking a premaxillary crest. The holotype of Kunpengopterus sinensis (IVPP V 16047) and ZMNH M8802/IVPP V 18043, an individual that was associated with eggs, lack an ossified cranial crest (Wang et al. 2010, 2015, Lü et al. 2011a, Figs. 1a, 1b, 2a, 2d).

Regarding the crested wukongopterids, there is some variation. Cheng et al. (2016) described a specimen (IVPP V 17959) that presents a crest 
starting anterior to the anterior margin of the nasoantorbital fenestra and that clearly does not reach the posterior region of the nasoantorbital fenestra what is confirmed by the lack of impression in the sediment matrix of this very compacted material (Figs. 1g, 1h, 2e).

The holotype of Darwinopterus modularis (ZMNH M8782) preserves an incomplete
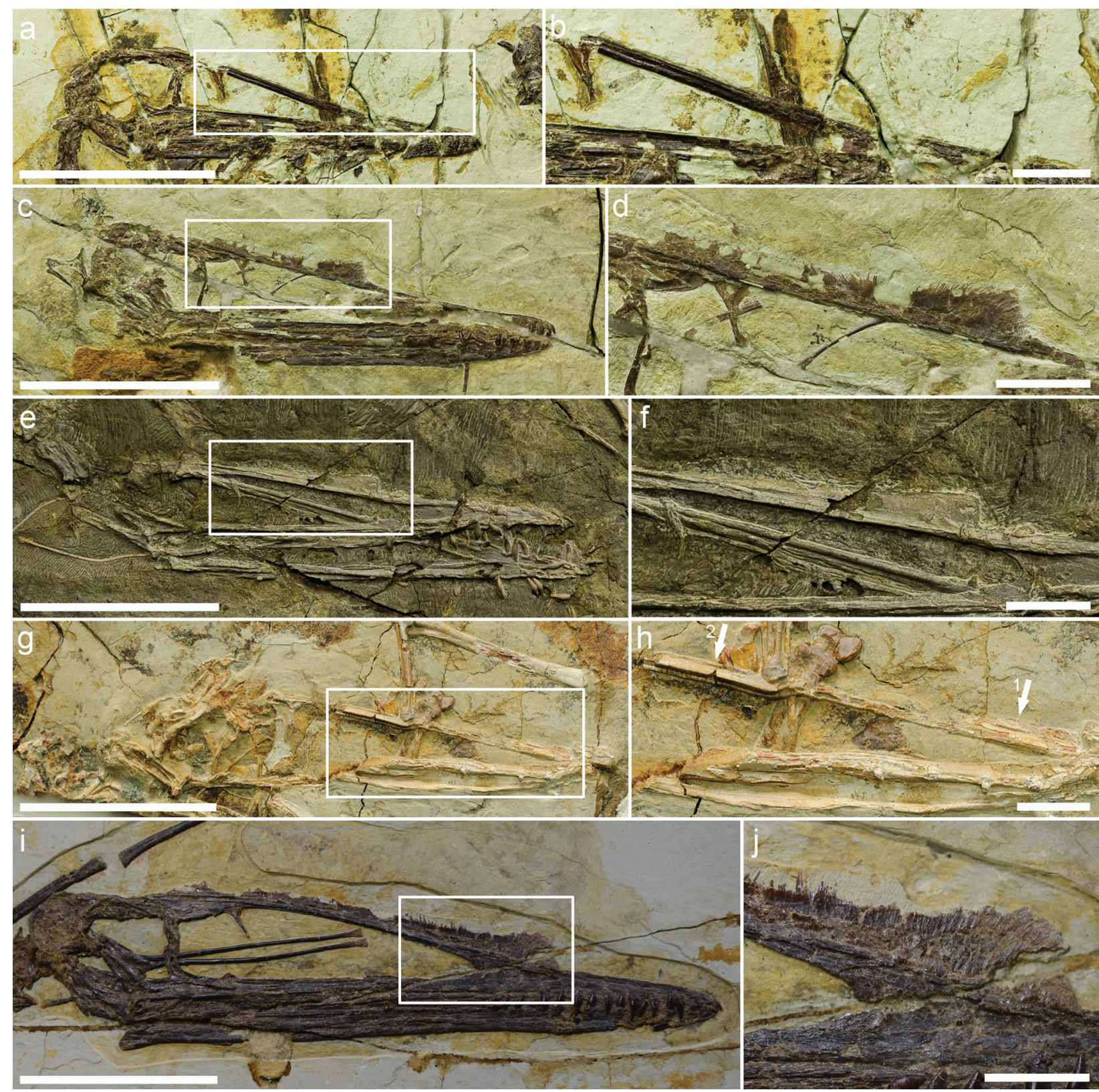

Figure 1 - The variation of cranial crest within the Wukongopteridae. Kunpengopterus sinensis (IVPP V 16047), (a) complete skull and (b) close-up of the area in the white frame of a, showing the flat crestless skull roof; holotype of Darwinopterus linglongtaensis (IVPP V 16049), (c) complete skull and (d) close-up of the area in the white frame of c; new specimen (IVPP V 17957), (e) complete skull (inverted), and (f) close-up of the area in the white frame of e; IVPP V 17959 (g) complete skull (inverted), and (h) close-up of the area in the white frame of $g$, with arrow 1 pointing at the low premaxillary crest and arrow 2 pointing at the crestless middle portion of the premaxilla; Darwinopterus robustodens (holotype, HGM 41HIII-0309A) (i) complete skull based on Lü et al. 2011b), and (j) close-up of the area in the white frame of i. Scale bar: 50mm in a, c, e, g, i; 10mm in b, d, f, h, j (see the colors in the online version). 
a

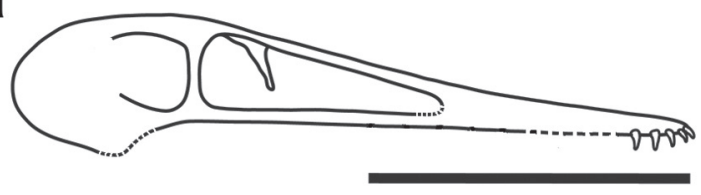

b

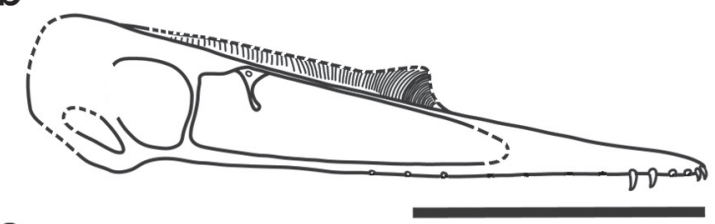

C

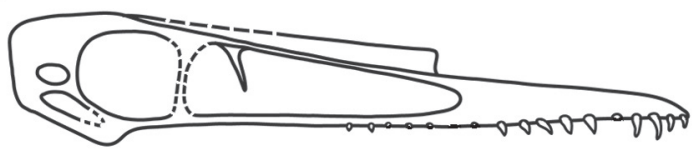

d

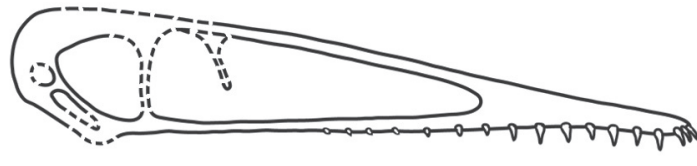

e

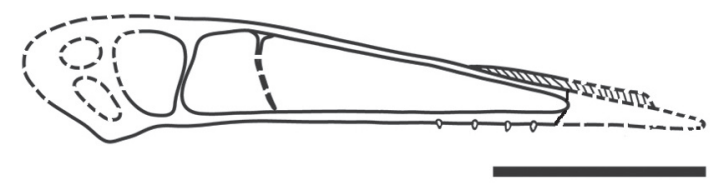

f

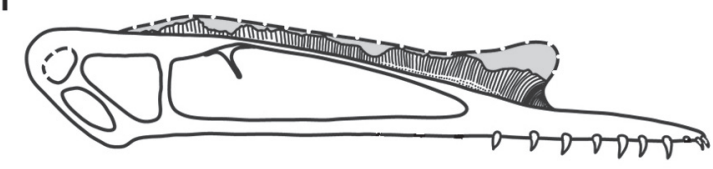

g

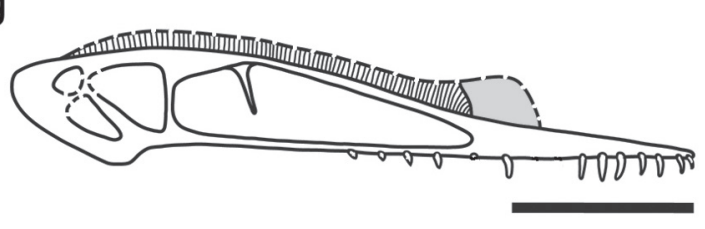

Figure 2 - Reconstruction of the various cranial crests of the Wukongopteridae. (a) Kunpengopterus sinensis (based on Wang et al. 2010); (b) Darwinopterus linglongtaensis (based on Wang et al. 2010); (c) new specimen (IVPP V 17957); (d) ZMNH M8802 (female, modified Lü et al. 2011a); (e) IVPP V 17959 (based on Cheng et al. 2016); (f) Darwinopterus robustodens (based on Lü et al. 2011b, (g) Darwinopterus modularis (holotype, based on Lü et al. 2010). Reconstruction of the crests in grey. Scale bar: $50 \mathrm{~mm}$. premaxillary crest that lacks the portion above the anterior margin of the nasoantorbital fenestra (Lü et al. 2010, Fig. 2g). According to the illustration provided in the original description (Lü et al. 2010), the crest becomes taller at the anterior part of the preserved portion and extends posteriorly above the orbit. The crest presents sub-vertical fiber-like structures and bears a serrated dorsal margin, that could indicate a soft tissue extension.

Compared to other wukongopterid skulls, Darwinopterus linglongtaensis (IVPP V 16049) preserves a rather large premaxillary crest (Figs. $1 \mathrm{c}, 1 \mathrm{~d}, 2 \mathrm{~b})$, that is smaller in respect of the one of Darwinopterus modularis (ZMNH M8782) and the one of Darwinopterus robustodens (HGM 41HIII0309A). It also shows a serrated dorsal margin, with the posterior portion partly preserved as an impression. The crest starts posterior to the anterior margin of the nasoantorbital fenestra and reaches the middle region of the orbit. Most of the dorsal margin of this structure is sub-parallel to the skull roof, but towards the anterior end it becomes taller forming a triangular structure in lateral view. The crest also shows fiber-like striations on the lateral surface that follow a sub-vertical pattern, becoming strongly curved anteriorly (Figs. 1d, 2b).

The holotype of Darwinopterus robustodens (HGM 41HIII-0309A) preserves a nearly complete premaxillary crest with a serrated dorsal margin (Lü et al. 2011b, Figs. 1i, 1j, 2f). The crest starts anterior to the nasoantorbital fenestra and is about one third longer than the nasoantorbital fenestra. Based on the impression in the matrix, the crest extends posteriorly above the orbit, similar to the condition present in Darwinopterus linglongtaensis (Figs. 1c, 2b). As the former, also this specimen shows fiber-like structures on the lateral surface of the crest that get curved and more marked towards the anterior end (Figs. 1j, 2f).

The new specimen (IVPP V 17957) shows a crest that is quite different from the previous ones. It starts posterior to the anterior margin of 
the nasoantorbital fenestra, albeit more anterior than Darwinopterus linglongtaensis and extends posteriorly. It is much lower than in other crested wukongopterids, except for IVPP V 17959 and based on the preserved portion, reached the orbits (Figs. 1e, 1f, 2c). The lateral surface of the crest is smooth, differing from all other wukongopterid crests, showing a straight dorsal margin. The anterior end of the crest lacks an extensive dorsal projection as the one found in Darwinopterus linglongtaensis and Darwinopterus robustodens (Figs. 1d, 1f, 1g, 2b, 2c, 2f).

\section{DISCUSSION}

The function of "bizarre structures" (Padian and Horner 2011) and their variability in reptiles, including pterosaurs, has long been a concern among researchers (e.g., Arthaber 1922). Several authors have proposed a variety of functions for the pterosaurian cranial crests, ranging from aerodynamics (e.g., Kripp 1943, Bramwell and Whitfield 1974, Kellner and Campos 2002b) to thermoregulation (Kellner 1989, Kellner and Campos 2002a).

In a very influential paper, Bennett (1992) argued that the large collection of Pteranodon specimens, a Late Cretaceous pterodactyloid from North America, could be divided into size classes suggesting sexually dimorphism. According to him, small individuals with small cranial crests show a pelvis with a large pelvic canal while the reverse is true for larger individuals (i.e., large cranial crest - small pelvic canal). However, there is no direct association of the skulls and pelves that could back this hypothesis (e.g., Kellner and Tomida 2000). Furthermore, it has been suggested that, at least theoretically, the differences found by Bennett (1992) could be accounted for ontogeny and taxonomy (Tomkins et al. 2010). In fact, a re-evaluation of several specimens attributed to Pteranodon has shown that in some cases there are sufficient morphological differences other than the shape and size of the cranial crest, supporting a larger taxonomic diversity within what can be called the Pteranodon-complex (Kellner 2010).

In any case, it should be noted that since both morphs of Pteranodon, which supposedly represent males and females, bear crests (Bennett 1992, Hone et al. 2012), it is not the presence but the expression in terms of sizes and shapes of these structures that might be regarded as sexually dimorphic. This last notion was recently supported by the exceptional discovery of the tapejarin tapejarid Cainajara dobruskii in the southern part of Brazil, represented by dozens of individuals of different ontogenetic stages and potentially different sexes. It could be determined that right from a very early ontogenetic stage, this pterosaur bore a cranial crest (Manzig et al. 2014).

In order to explain the cranial crests or other over developed structures as sexually selected traits demands considerable sexual dimorphism (Padian and Horner 2011), but this has never been adequately established in pterosaurs. Despite the heated debate on this topic (e.g., Hone et al. 2012, Knell et al. 2013a, b, Padian and Horner 2013) the fact is that sexual dimorphism (and several other biological questions) are difficult to be tested without a large number of individuals that belong to the same or closely related populations (Kellner et al. 2013), what has only rarely been the case for pterosaurs (Grellet-Tinner et al. 2014, Manzig et al. 2014, Wang et al. 2014a).

Regarding these flying reptiles, an interesting discovery shed some light on the question of the cranial crests being sexually dimorphic. In a Cretaceous deposit from northwestern China, dozens of individuals of the pterodactyloid pterosaur Hamipterus tianshanensis of different ontogenetic stages were found (albeit not covering the same range as in the Caiuajara material). Since this Chinese material is associated with eggs, it is expected that males and females are present in this collection. Hamipterus tianshanensis bears a 
premaxillary crest that, in similar sized individuals, showed consistently two distinct morphotypes: one with larger and more robust crests, and the second with smaller and more delicate crests. These morphotypes were tentatively regarded as males and females, respectively (Wang et al. 2014a). Although the Chinese specimens collected so far are disarticulated and pelvic elements that might allow a more detailed assessment of crest-independent sexual dimorphism characters (Padian and Horner 2011) are rare, this occurrence constitute, to our knowledge, the best argument favoring sexual dimorphism expressed by cranial crests. Granted, it should be noted that in this taxon, the sizes of these structures are not particularly large as compared to other pterosaurs such as Thalassodromeus, Pteranodon, and Geosternbergia (Bennett 1992, Kellner and Campos 2002a, Kellner 2010). Once again, this is another example where the expression of the crest and not its presence shows potential for sexual dimorphism.

The hypothesis put forward by Lü et al. (2011a) and that was subsequently used as example for sexual selection in the fossil record (Knell et al. 2013a) defends that the wukongopterid Darwinopterus is sexually dimorphic, with males having a premaxillary crest that is absent in females. Their argument resides in two main points: the direct association of a specimen attributed (even if not explicitly) to the species Darwinopterus modularis, and the comparisons of the pelves of four individuals, two of which were regarded as males and two as females (Lü et al. 2011 a suppl. material).

There is no question that the main specimen (ZMNH M8802/IVPP V 18043) is crestless (Fig. $2 \mathrm{~d}$ ) and was associated with not only one, but two eggs, one still inside the body of the animal (Wang et al. 2015) and therefore can be confidently regarded as a female. However, there are other aspects of the study of Lü et al. (2011a) which are more problematic. The skull of the second supposed female (YH-2000) is badly preserved (see Lü et al.
2010: fig. 2f), lacking most of the dorsal portion, impeding the determination if a crest is present or not. In their original description, Lü et al. (2011a) implied that the wukongopterid specimen $\mathrm{ZMNH}$ M8802/IVPP V 18043 represented the species Darwinopterus modularis, failing to acknowledge the existence of other members of this clade (Wang et al. 2009, 2010). Oddly, in the same year, Lü et al. (2011b) reinterpreted one of the original males (HGM 41HIII-0309A; Lü et al. 2011a) as a new species, Darwinopterus robustodens (still not acknowledging previous studies on the Wukongopteridae).

We have examined the question about the sizes of the pelvis in more debt. Although Lü et al. (2011a) advocated the presence of two males and females, actually regarding the dimensions of the pelvis, there are only two specimens where this portion of the skeleton can be examined in more detail, one of each gender: ZMNH M8782 the holotype of Darwinopterus modularis, regarded as a male, and ZMNH M8802/IVPP V 18043, the indisputable female. According to Lü et al. (2011a), both pelves show quite similar dimensions, but the crested specimen (ZMNH M8782) is about $13 \%$ larger (based on the length of the humeri), a difference which, according to our estimates, might have been even greater (see Table I). Therefore, according to these authors, the pelvis of $\mathrm{ZMNH}$ M8782 is proportionally smaller than the one of the female (ZMNH M8802/IVPP V 18043).

We have measured the pelvis of the specimen IVPP V 16049 (holotype of Darwinopterus linglongtaensis, Wang et al. 2010; Table II), that bears a developed premaxillary crest and has reached about $68 \%$ the size of the holotype of Darwinopterus modularis (ZMNH M8782; Table I). If Lü et al. (2011a) are correct, IVPP V 16049 should represent a male individual. We have followed the procedures outlined by them regarding the measurements of the pelvis (see Lü et al. 2011a: suppl. material), which differ from the 
TABLE I

Measurements of the length of skull, humerus and ulna of the Wukongopteridae, from the smallest to the largest individual based on wingspan (in $\mathrm{mm}$ ).

\begin{tabular}{|c|c|c|c|c|c|}
\hline Taxa & sq-pm & hu & $\mathrm{ul} / \mathrm{ra}$ & maxws & Reference \\
\hline $\begin{array}{l}\text { Darwinopterus linglongtaensis } \\
\text { (IVPP V 16049) }\end{array}$ & 119.2 & 40.4 & 58.0 & 708.2 & Wang et al. 2010 and this paper (Table III) \\
\hline $\begin{array}{l}\text { Wukongopterus lii } \\
\text { (IVPP V 15113) }\end{array}$ & - & $\sim 38.7$ & $\sim 62.1$ & $\sim 734.0$ & Wang et al. 2010 and this paper (Table III) \\
\hline $\begin{array}{l}\text { Kunpengopterus sinensis } \\
\text { (IVPP V 16047) }\end{array}$ & 106.9 & $\sim 36.2$ & 59.2 & $\sim 734.4$ & Wang et al. 2010 and this paper (Table III) \\
\hline $\begin{array}{l}\text { Darwinopterus modularis } \\
\text { (referred specimen, YH-2000) }\end{array}$ & est. 140 & 44 & 64 & 760.8 & Lü et al. 2010 and this paper (Table III) \\
\hline IVPP V 17957 & est. 130.0 & 44.9 & 62.8 & 778.8 & This paper (Table III) \\
\hline IVPP V 17959 & est. 145.0 & est. 41.0 & 67.3 & est. 782.2 & Cheng et al. 2016 and this paper (Table III) \\
\hline ZMNH M8802/IVPP V 18043 & 150 & 52 & 70 & est. 879.8 & Lü et al. 2011a \\
\hline $\begin{array}{l}\text { Darwinopterus robustodens } \\
\text { (HGM 41HIII-0309A) }\end{array}$ & 173.2 & 52.8 & 85.4 & 996.6 & This paper (Table III) \\
\hline $\begin{array}{l}\text { Darwinopterus modularis } \\
\text { (holotype, ZMNH M8782) }\end{array}$ & 185 & 59 & 87 & est. 1074.9 & Lü et al. 2010 \\
\hline \multicolumn{6}{|c|}{$\begin{array}{l}\text {-, not preserved; est, estimated value. Abbreviations: hu, humerus; maxws, maximized wingspan; sq-pm, squamosal to the tip of } \\
\text { premaxilla; ul, ulna. The maximized wingspan (maxws=cor }+\mathrm{hu}+\mathrm{ul} / \mathrm{ra}+\mathrm{car}+\mathrm{mcIV}+\mathrm{ph} 1 \mathrm{~d} 4+\mathrm{ph} 2 \mathrm{~d} 4+\mathrm{ph} 3 \mathrm{~d} 4+\mathrm{ph} 4 \mathrm{~d} 4 \text {, Kellner et al. } \\
\text { 2013; abbreviations and measurements see Table III) of Kunpengopterus sinensis, Darwinopterus linglongtaensis, Wukongopterus } \\
\text { lii, YH-2000, and Darwinopterus robustodens is based on complete forelimb elements plus the coracoid, while that of IVPP } \\
\text { V 17959, ZMNH M8802/IVPP V 18043, and the holotype of Darwinopterus modularis is estimated by the ratio between the } \\
\text { preserved elements and maximized wingspan compared to complete specimens. }\end{array}$} \\
\hline
\end{tabular}

TABLE II

Measurements (in mm) and ratio of the pelvis and humerus of Darwinopterus modularis, Darwinopterus linglongtaensis, and one female wukongopterid.

\begin{tabular}{|c|c|c|c|c|c|c|c|c|c|c|}
\hline & hu & $\mathrm{sl}$ & $\mathrm{pl}$ & $\mathrm{pd}$ & pw & $\mathrm{pl} / \mathrm{pd}$ & $\mathrm{pw} / \mathrm{pd}$ & $\mathrm{pl} / \mathrm{pw}$ & $\mathrm{sl} / \mathrm{pd}$ & \\
\hline $\begin{array}{l}\text { supposed male } \\
\text { Darwinopterus modularis } \\
\text { (holotype, ZMNH M8782) }\end{array}$ & 59.0 & est. 22.0 & 37.5 & 20.0 & 19.5 & 1.86 & 0.98 & 1.92 & 1.10 & $\begin{array}{l}\text { Lü et al. 2011a } \\
\text { and this paper }\end{array}$ \\
\hline $\begin{array}{l}\text { supposed female } \\
\text { "Darwinopterus modularis" } \\
\text { (ZMNH M } 8802 \text { or IVPP V 18403) }\end{array}$ & 52.0 & est. 19.0 & 36.0 & 19.5 & 20.0 & 1.85 & 1.03 & 1.80 & 0.97 & $\begin{array}{l}\text { Lü et al. 2011a } \\
\text { and this paper }\end{array}$ \\
\hline $\begin{array}{l}\text { Darwinopterus linglongtaensis } \\
\text { (holotype, IVPP V 16049) }\end{array}$ & 40.4 & 16.3 & 30.2 & 20.6 & $\sim 18.0$ & 1.47 & 0.87 & 1.68 & 0.79 & This paper \\
\hline $\begin{array}{l}\text { ZMNH M8782 / } \\
\text { ZMNH M8802 or IVPP V } 18403\end{array}$ & 1.13 & 1.16 & 1.04 & 1.03 & 0.98 & & & & & $\begin{array}{l}\text { Lü et al. 2011a } \\
\text { and this paper }\end{array}$ \\
\hline ZMNH M8782 / IVPP V 16049 & 1.46 & 1.35 & 1.24 & 0.97 & 1.08 & & & & & This paper \\
\hline $\begin{array}{l}\text { ZMNH M8802 or IVPP V } 18403 \\
\text { / IVPP V } 16049\end{array}$ & 1.29 & 1.17 & 1.19 & 0.95 & 1.11 & & & & & This paper \\
\hline
\end{tabular}

$\sim$, estimate based on the third sacral vertebra; est, estimated value based on pictures. Abbreviations: hu, humerus; pd, pelvis depth from dorsal margin of the ilium to the ventral margin of the puboischiadic plate at level of the acetabulum; pl, pelvis length from anterior tip of preacetabular process of ilium to posterior tip of postacetabular process of ilium; pw, pelvis width between the acetabula; sl, length of sacral vertebrae. 
TABLE III

Measurements of IVPP V 17957 and other published wukongopterid specimens (in mm).

\begin{tabular}{|c|c|c|c|c|c|c|c|c|c|}
\hline Bone/Taxa & 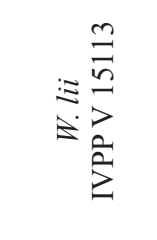 & 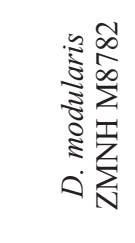 & 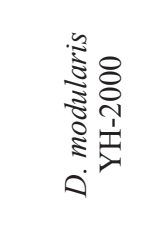 & 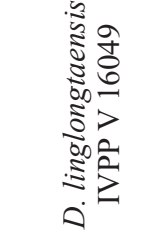 & 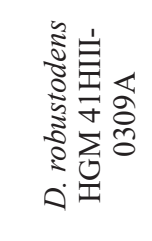 & 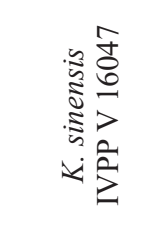 & 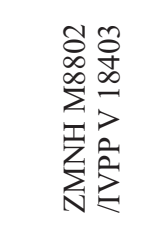 & $\begin{array}{l}\frac{2}{2} \\
2 \\
\frac{1}{2} \\
2 \\
2\end{array}$ & $\begin{array}{l}\frac{n}{2} \\
\frac{2}{2} \\
\frac{2}{2} \\
2\end{array}$ \\
\hline sq-pm & - & 185 & est 140 & $\sim 119.2$ & 173.2 & 106.9 & 150 & est 145 & est. 130 \\
\hline ros & 32.6 & & & $\sim 30.3$ & 61.7 & $\sim 40.5$ & 46 & - & 40.1 \\
\hline naof & - & 82 & - & $\sim 57.9$ & 77.7 & $\sim 37.9$ & $* 72$ & est 80 & - \\
\hline lower jaw & 103.2 & 157 & 115 & 102.4 & 151.3 & 89.5 & est 125 & est 130 & 106.8 \\
\hline man.sys & 19.5 & & & $\sim 23.6$ & - & - & 34 & est 30 & 25.5 \\
\hline sca & $\begin{array}{l}34.1(\mathrm{r}) \\
32.9(1)\end{array}$ & $>25$ & 27 & $31.1(\mathrm{r})$ & $37.3(\mathrm{r})$ & $\sim 28.8(\mathrm{r})$ & 34 & - & $\begin{array}{l}31.8(\mathrm{r}) \\
32.3(1)\end{array}$ \\
\hline cor & $\sim 25.3(\mathrm{r})$ & 34 & 26 & $\begin{array}{l}24.9(\mathrm{r}) \\
26.3(1)\end{array}$ & $34.6(\mathrm{r})$ & $\sim 23.8(1)$ & & - & 28.4(r) \\
\hline hu & $\sim 38.7(\mathrm{r})$ & 59 & 44 & $\begin{array}{l}40.4(\mathrm{r}) \\
39.9(1)\end{array}$ & $\begin{array}{l}52.8(\mathrm{r}) \\
53.3(1)\end{array}$ & $\sim 36.2(\mathrm{r})$ & 52 & est 41(r) & $\begin{array}{l}44.9(\mathrm{r}) \\
43.6(1)\end{array}$ \\
\hline $\mathrm{ul} / \mathrm{ra}$ & $\sim 62.1(\mathrm{r})$ & 87 & 64 & $\begin{array}{l}58.0(\mathrm{r}) \\
61.2(1)\end{array}$ & $\begin{array}{l}85.4(\mathrm{r}) \\
82.3(\mathrm{l})\end{array}$ & $\sim 59.2(1)$ & 70 & 67.3(r) & $\begin{array}{l}62.8(\mathrm{r}) \\
62.4(1)\end{array}$ \\
\hline car & $5.7(\mathrm{r})$ & & 5.4 & $\begin{array}{l}4.6(r) \\
4.5(1)\end{array}$ & $\begin{array}{l}7.4(\mathrm{r}) \\
7.2(1)\end{array}$ & $4.8(\mathrm{r})$ & - & $4.3(1)$ & $5.2(1)$ \\
\hline mcIV & $22.9(1)$ & 36 & 26 & $\begin{array}{l}22.5(r) \\
23.6(1)\end{array}$ & $\begin{array}{l}33.1(\mathrm{r}) \\
30.7(1)\end{array}$ & $\sim 23.0(1)$ & & $\begin{array}{l}26.5(\mathrm{r}) \\
27.6(1)\end{array}$ & $26.6(1)$ \\
\hline ph1d4 & $\sim 45.7(\mathrm{r})$ & 75 & 48 & $\begin{array}{l}46.2(\mathrm{r}) \\
44.4(1)\end{array}$ & $\begin{array}{l}\text { 63.9(r) } \\
61.1(1)\end{array}$ & $54.2(\mathrm{r})$ & & $\sim 55.3(\mathrm{r})$ & $\begin{array}{l}54.1(\mathrm{r}) \\
53.3(1)\end{array}$ \\
\hline $\mathrm{ph} 2 \mathrm{~d} 4$ & $56.8(\mathrm{r})$ & - & 55 & $\begin{array}{l}50.7(\mathrm{r}) \\
52.1(1)\end{array}$ & $\begin{array}{l}75.0(\mathrm{r}) \\
74.3(1)\end{array}$ & $58.0(\mathrm{r})$ & & $\sim 59.8(\mathrm{r})$ & $\begin{array}{l}59.5(\mathrm{r}) \\
58.6(1)\end{array}$ \\
\hline ph3d4 & $\begin{array}{l}58.3(\mathrm{r}) \\
59.3(1)\end{array}$ & - & 59 & $\begin{array}{l}53.2(\mathrm{r}) \\
53.7(1)\end{array}$ & $\begin{array}{l}78.1(r) \\
75.7(1)\end{array}$ & $59.2(\mathrm{r})$ & & - & $\begin{array}{l}58.5(\mathrm{r}) \\
57.7(1)\end{array}$ \\
\hline $\mathrm{ph} 4 \mathrm{~d} 4$ & $51.5(1)$ & - & 53 & $\begin{array}{l}53.6(\mathrm{r}) \\
53.7(1)\end{array}$ & $68.0(\mathrm{r})$ & $\sim 48.8(1)$ & & - & 49.4(r) \\
\hline fe & $\begin{array}{l}33.3(\mathrm{r}) \\
35.6(1)\end{array}$ & - & 40 & $\begin{array}{l}39.4(\mathrm{r}) \\
40.1(1)\end{array}$ & $43.5(\mathrm{r})$ & $\begin{array}{l}\sim 39.3(\mathrm{r}) \\
\sim 41.1(1) \\
\end{array}$ & 41 & - & $\begin{array}{l}42.2(r) \\
42.7(1)\end{array}$ \\
\hline ti & $52.8(\mathrm{r})$ & - & 54 & $\begin{array}{l}49.8(\mathrm{r}) \\
49.6(1)\end{array}$ & $61.4(1)$ & $54.5(1)$ & 61 & - & - \\
\hline $\mathrm{mt} 3$ & $\begin{array}{r}\sim 17.2(\mathrm{r}) \\
16.8(1)\end{array}$ & 23 & 17 & $17.0(\mathrm{r})$ & $\begin{array}{l}21.5(\mathrm{r}) \\
20.6(1)\end{array}$ & $\begin{array}{l}21.8(\mathrm{r}) \\
20.7(1)\end{array}$ & 20 & - & - \\
\hline $\mathrm{mt} 4$ & $\begin{array}{r}\sim 14.5(\mathrm{r}) \\
15.0(1) \\
\end{array}$ & & & $\begin{array}{l}14.2(\mathrm{r}) \\
14.2(1)\end{array}$ & $\begin{array}{l}18.5(\mathrm{r}) \\
17.6(1)\end{array}$ & 17.9(r) & 16 & 15.1 & - \\
\hline pph1d5 & $\begin{array}{l}13.9(\mathrm{r}) \\
13.7(1)\end{array}$ & & & $\begin{array}{l}12.8(\mathrm{r}) \\
12.1(\mathrm{l})\end{array}$ & $\begin{array}{l}18.1(\mathrm{r}) \\
18.0(\mathrm{l})\end{array}$ & $11.2(\mathrm{r})$ & 18.5 & - & - \\
\hline \multirow[t]{2}{*}{ ptd } & $>7.3(\mathrm{r})$ & - & 26 & $28.9(1)$ & $34.0(1)$ & $\sim 25.8(1)$ & 25 & $24.9(1)$ & est 31(r) \\
\hline & $\begin{array}{l}\text { Wang et al. } \\
2010 \text { and } \\
\text { this paper }\end{array}$ & $\begin{array}{l}\text { Lü et al. } \\
2010\end{array}$ & $\begin{array}{l}\text { Lü et al. } \\
2010 \text { and } \\
\text { this paper }\end{array}$ & $\begin{array}{l}\text { Wang et al. } \\
2010 \text { and } \\
\text { this paper }\end{array}$ & This paper & $\begin{array}{l}\text { Wang et al. } \\
2010 \text { and } \\
\text { this paper }\end{array}$ & $\begin{array}{l}\text { Lü et al. } \\
\text { 2011a } \\
\text { and this } \\
\text { paper }\end{array}$ & $\begin{array}{l}\text { Cheng et al. } \\
2016 \text { and } \\
\text { this paper }\end{array}$ & This paper \\
\hline
\end{tabular}

-, not preserved; *, corrected in this paper based on pictures; est, estimated value. Abbreviations: car, carpus; cor, coracoid; fe, femur; hu, humerus; 1, left; man.sys, mandibular symphysis; mcIV, metacarple IV; mt3-4, metatarsle 3-4; naof, nasoantorbital fenestra; ph1-4d4, first to fourth phalanx of manual digit IV; pph1d5, first phalanx of pedal digit V; ptd, pteroid; r, right; ra, radius; ros, rostrum; sca, scapula; sq-pm, tip of premaxilla to posterior end of squamosal; ti, tibia; ul, ulna. 
procedures adopted by Bennett (1992). Comparing the size and proportions of the pelvic elements of these wukongopterid specimens, however, we could establish that the pelvis of IVPP V 16049 is proportionally larger and deeper than the one of the holotype of Darwinopterus modularis (ZMNH M8782; Table II). Moreover, when we compare the measurements of the indisputable female $(\mathrm{ZMNH}$ M8802/IVPP V 18043), the proportions of that pelvis is not much different from the holotype of Darwinopterus modularis (ZMNH M8782; Table II), meaning that it could not have had a wider pelvic canal (contra Lü et al. 2011a). Actually, if all three specimens represent the same species, IVPP V 16049, which bears a crest, has the deepest pelvis, implying in a proportionally larger pelvic canal (Table II), and according to previous studies on this subject (Bennett 1992, Lü et al. 2011a), would have to be interpreted as a female. And if so, just for the sake of argumentation, it would be unusual to consider these two specimens (ZMNH M8802/ IVPP V 18043 and IVPP V 16049) as representing the same species.

Based on the available wukongopterid skulls (including the new specimen - IVPP V 17957), there are at least three conditions regarding premaxillary crests: absent (Figs. 1a, 1b, 2a, 2d), present and limited posteriorly to the anterior end of the nasoantorbital fenestra (Figs. 1c-f, 2b, 2c), and extended anterior to the nasoantorbital fenestra (Figs. 1i, 1j, 2f, 2g). A fourth condition can also be advocated based on the specimen IVPP V 17959, where the cranial crest is very reduced (Figs. $1 \mathrm{~g}, 1 \mathrm{~h}$, 2e). One could try to argue that, if not taxonomic, this variation could reflect different ontogenetic stages, with young individuals (Fig. 2a) being crestless, that would at a certain ontogenetic stage develop a crest above the nasoantorbital fenestra (Fig. 2b) and expand this crest anteriorly in older (and larger) individuals (Figs. 2f, 2g). However, the crestless and smallest individual (based on the length of humerus, IVPP V 16047, Fig. 2a, Table I) has a larger (more than 3.6\%) maximum wingspan than the second smallest individual (based on the length of humerus, IVPP V 16049, Fig. 2b, Table I). Even though considering the wingspan as individual differences, it still seems difficult that the appearance of the crest would be a sudden event in such close sized animals. In the best example of an ontogenetic series within pterosaurs that is represented by Caiuajara (admittedly very distantly related to the Wukongopteridae), there seems a continuum in the appearance and development of the cranial crest, present in this taxon at a very young ontogenetic stage (Manzig et al. 2014). Furthermore, there are other important morphological differences that separate Kunpengopterus sinensis (IVPP V 16047) and Darwinopterus linglongtaensis (IVPP V 16049) (see Wang et al. 2010).

Still pursuing the potential ontogenetic argument, the shapes and the sizes of the crests also do not seem to follow an ontogenetic pattern (compare Figs. $2 \mathrm{~b}$ with $2 \mathrm{c}$ and $2 \mathrm{f}$ ). Secondly, the shapes and the external surfaces of the crests (i.e., smooth or fibrous) also vary to a great degree independent of the sizes of the individuals (compare Figs. 1d with 1f and $1 \mathrm{~g}$ ).

\section{CONCLUSION}

The function of cranial crests in pterosaurs will be a matter of contempt until more material becomes available. Although the comparisons of the pelvic elements of wukongopterids is interesting, one cannot overemphasize the reduced number of specimens on which this and other studies are based. Variations introduced by taphonomy, allied with morphological differences as a result of ontogeny and other factors cannot be adequately assessed with three or so individuals. Notwithstanding these shortcomings, the explanation of the evolutionary function of cranial crests as sexual dimorphism (including mutual sexual selection, Hone et al. 2012) should not be used as the default option. As has been pointed out before (e.g., Kellner and 
Campos 2002a, 2002b), it seems quite unlikely that once a pterosaur developed a cranial crest (as perhaps the so called "bizarre structures" in other reptiles), this structure could not have performed a variety of functions. Despite the limitation of the available data, it seems difficult not to acknowledge that these quite distinct anatomical features have played a major role in species recognition, as has been put forward for other reptiles (e.g., Padian and Horner 2011). This has been shown to be true at least for some material of the Pteranodon-complex and seems also to have been the case for the Wukongopteridae. Perhaps more detailed studies of deposits with large amount of specimens that might have been part of the same or closely related populations like the occurrences of Cainajara dobruskii and Hamipterus tianshanensis (and others that might come to light) have the potential to provide a step further into the discussion of several paleobiological questions concerning flying reptiles, including sexual dimorphism and ontogeny (Kellner 2015). Meanwhile the variation in shapes and sizes of cranial crests that are found in pterosaurs, associated with other morphological features, should not be understated as being a powerful tool for understanding their diversity.

\section{ACKNOWLEDGMENTS}

We thank Long Xiang (IVPP) for the preparation of the specimen (IVPP V 17957) and Wei Gao (IVPP) for some of the photos that illustrate this article. Li Xu and Songhai Jia (HGM) and the organizers of the 2010 International Symposium on Pterosaurs held in Beijing (China) are thanked for providing one of the authors (Xin Cheng) access to Darwinopterus robustodens and YH-2000 (referred to Darwinopterus modularis), respectively. We also acknowledge Felipe Pinheiro (Universidade Federal do Pampa, Rio Grande do Sul) and an unknown reviewer for comments and suggestions on earlier version of this manuscript. This study was supported by the National Natural Science
Foundation of China (41572020, 41688103), the Major Research plan of the National Natural Science Foundation of China (91514302), the Key Laboratory of Economic Stratigraphy and Palaeogeography, Nanjing Institute of Geology and Palaeontology (CAS), the Hundred Talents Project of Chinese Academy of Sciences, the National Science Fund for Distinguished Young Scholars (40825005), and the National Key Basic Research Program of China (2012CB821900). Alexander Kellner acknowledges founding from the Fundação Carlos Chagas Filho de Amparo à Pesquisa do Rio de Janeiro (FAPERJ \# E-26/202.893/2015) and the Conselho Nacional de Desenvolvimento Científico e Tecnológico (CNPq \# 304780/2013-8).

\section{REFERENCES}

ANDRES B, CLARK JM AND XU X. 2014. The earliest pterodactyloid and the origin of the group. Curr Biol 24: 1-6.

ARTHABER G. 1922. Über Entwicklung, Ausbildung und Absterben der Flugsaurier. Pal Zeitschr 4: 1-47.

BENNETT SC. 1992. Sexual dimorphism of Pteranodon and other pterosaurs, with comments on cranial crests. J Vert Paleont 12: 422-434.

BRAMWELL CD AND WHITFIELD GR. 1974. Biomechanics of Pteranodon. Phil Trans R Soc Lond B 267: 503-581.

CAMPOS DA AND KELLNER AWA. 1985. Panorama of the flying reptiles study in Brazil and South America. An Acad Bras Cienc 57: 453-466.

CHENG X, JIANG SX, WANG XL AND KELLNER AWA. 2016. New information on the Wukongopteridae (Pterosauria) revealed by a new specimen from the Jurassic of China. PeerJ 4: e2177.

CZERKAS SA AND JI Q. 2002. A new rhamphorhynchoid with a headcrest and complex integumentary structures. In: Czerkas SJ (Ed), Feathered Dinosaurs and the Origin of Flight. Utah: The Dinosaur Museum, p. 15-41.

DALLA VECCHIA FM. 2009. The first Italian specimen of Austriadactlyus cristatus (Diapsida, Pterosauria) from the Norian (Upper Triassic) of the Carnic Prealps. Riv Ital Paleont S 115: 291-304.

DALLA VECCHIAFM. 2014. Gli pterosauri triassici. Memorie del Museo Friulano di Storia Naturale, pubblicazione n. 54. Udine: Museo Friulano di Storia Naturale, p. 1-319.

GRELLET-TINNER G, THOMPSON MB, FIORELLI LE, ARGAÑARAZ E, CODORNIÚ L AND HECHENLEITNER EM. 2014. The first pterosaur 3-D egg: Implications for Pterodaustro guinazui nesting 
strategies, an Albian filter feeder pterosaur from central Argentina. Geosci Front 5: 759-765.

HONE DWE, NAISH D AND CUTHILL IC. 2012. Does mutual sexual selection explain the evolution of head crests in pterosaurs and dinosaurs? Lethaia 45: 139-156.

KELLNER AWA. 1989. A new edentate pterosaur of the Lower Cretaceous from the Araripe Basin, Northeast Brazil. An Acad Bras Cienc 61: 439-446.

KELLNER AWA. 2003. Pterosaur phylogeny and comments on the evolutionary history of the group. In: BUFFETAUT E AND MAZIN JM (Eds), Evolution and Palaeobiology of Pterosaurs. Geol Soc, London, Special Publications 217, p. 105-137.

KELLNER AWA. 2010. Comments on the Pteranodontidae (Pterosauria, Pterodactyloidea) with the description of two new species. An Acad Bras Cienc 82: 1063-1084.

KELLNER AWA. 2015. Comments on Triassic perosaurs with discussion about ontogeny and description of new taxa. An Acad Bras Cienc 87: 669-689.

KELLNER AWA AND CAMPOS DA. 2002a. The Function of the Cranial Crest and Jaws of a Unique Pterosaur from the Early Cretaceous of Brazil. Science 297: 389-392.

KELLNER AWA AND CAMPOS DA. 2002b. Form, function, and the flight of the pterosaur - response. Science 297: 2207-2208

KELLNER AWA, CAMPOS DA, SAYÃO JM, SARAIVA AAF, RODRIGUES T, OLIVEIRA G, CRUZ LA, COSTA FR, SILVA HP AND FERREIRA JS. 2013. The largest flying reptile from Gondwana: a new specimen of Tropeognathus cf. T. mesembrinus Wellnhofer, 1987 (Pterodactyloidea, Anhangueridae) and other large pterosaurs from the Romualdo Formation, Lower Cretaceous, Brazil. An Acad Bras Cienc 85: 113-135.

KELLNER AWA AND LANGSTON W JR. 1996. Cranial remains of Quetzalcoatlus (Pterosauria, Azhdarchidae) from Late Cretaceous sediments of Big Bend National Park, Texas. J Vert Paleont 16: 222-231.

KELLNER AWA AND TOMIDA Y. 2000. Description of a new species of Anhangueridae (Pterodactyloidea) with comments on the pterosaur fauna from the Santana Formation (Aptian-Albian), North eastern Brazil. Nat Sci Museum Monog 17: 1-135.

KNELL RJ, NAISH D, TOMKINS JL AND HONE DWE. 2013a. Sexual selection in prehistoric animals: detection and implications. Trends Ecol Evol 28: 38-47.

KNELL RJ, NAISH D, TOMKINS JL AND HONE DWE. 2013b. Is sexual selection defined by dimorphism alone? A reply to Padian and Horner. Trends Ecol Evol 28: 250-251.

KRIPP D. VON. 1943. Ein Lebensbild von Pteranodon ingens auf flugtechnischer Grundlage. Nova Acta Leopold, N.F. 12: $16-32$.

LÜ JC. 2009. A New Non-Pterodactyloid Pterosaur from Qinglong County, Hebei Province of China. Acta Geol Sin-Engl 83: 189-199.
LÜ JC, UNWIN DM, DEEMING DC, JIN XS, LIU YQ AND JI Q. 2011a. An egg-adult association, gender, and reproduction in pterosaurs. Science 331: 321-324.

LÜ JC, UNWIN DM, JIN XS, LIU YQ AND JI Q. 2010. Evidence for modular evolution in a long-tailed pterosaur with a pterodactyloid skull. Proc Roy Soc B-Biol Sci 277: 383 389.

LÜ JC, XU L, CHANG HL AND ZHANG XL. 2011b. A new darwinopterid pterosaur from the Middle Jurassic of western Liaoning, northeastern China and its ecological implications. Acta Geol Sin-Engl 85: 507-514.

MANZIG PC, KELLNER AWA, WEINSCHÜTZ LC, FRAGOSO CE, VEGA CS, GUIMARÃES GB, GODOY LC, LICCARDO A, RICETTI JH AND DE MOURA CC. 2014. Discovery of a rare bone bed in a Cretaceous desert with insights on ontogeny and behavior of flying reptiles. Plos One 9: e100005.

PADIAN K AND HORNER JR. 2011. The evolution of 'bizarre structures' in dinosaurs: biomechanics, sexual selection, social selection or species recognition? J Zool 283: 3-17.

PADIAN K AND HORNER JR. 2013. Misconceptions of sexual selection and species recognithion: a response to Knell et al. and to Mendelson and Shaw. Trends Ecol Evol 28: 249-250.

STECHER R. 2008. A new Triassic pterosaur from Switzerland (Central Austroalpine, Grisons), Raeticodactylus filisurensis gen. et sp. nov.. Swiss J Geosci 101: 185-201.

SULLIVAN C, WANG Y, HONE DWE, WANG YQ, XU X AND ZHANG FC. 2014. The vertebrates of the Jurassic Daohugou Biota of northeastern China. J Vert Paleont 34: 243-280.

TOMKINS JL, LEBAS NR, WITTON MP, MARTILL DM AND HUMPHRIES S. 2010. Positive allometry and the prehistory of sexual selection. Am Nat 176: 141-148.

WANG XL ET AL. 2015. Eggshell and histology provide insight on the life history of a pterosaur with two functional ovaries. An Acad Bras Cienc 87: 1599-1609.

WANG XL, KELLNER AWA, JIANG SX AND CHENG X. 2012. New toothed flying reptile from Asia close similarities between early Cretaceous pterosaur faunas from China and Brazil. Naturwissenschaften 99: 249-257.

WANG XL, KELLNER AWA, JIANG SX, CHENG X, MENG X AND RODRIGUES T. 2010. New long-tailed pterosaurs (Wukongopteridae) from western Liaoning, China. An Acad Bras Cienc 82: 1045-1062.

WANG XL, KELLNER AWA, JIANG SX AND MENG X. 2009. An unusual long-tailed pterosaur with elongated neck from western Liaoning of China. An Acad Bras Cienc 81: 793-812.

WANG XL ET AL. 2014a. Sexually dimorphic tridimensionally preserved pterosaurs and their eggs from China. Curr Biol 24: 1323-1330. 
WANG XL, RODRIGUES T, JIANG SX, CHENG X AND KELLNER AWA. 2014b. An Early Cretaceous pterosaur with an unusual mandibular crest from China and a potential novel feeding strategy. Sci Rep 4: 6329.

WANG XL AND ZHOU ZH. 2003. A new pterosaur (Pterodactyloidea Tapejaridae) from the Early Cretaceous Jiufotang Formation of western Liaoning China and its implications for biostratigraphy. Chin Sci Bull 48: 16-23.

WELLNHOFER P. 1987. New crested pterosaurs from the Lower Cretaceous of Brazil. Mitt Bayer Staatsslg Paläont hist Geol 27: 175-186.
WELLNHOFER P. 1991. The Illustrated Encyclopedia of Pterosaurs. London: Salamander Books. 1-192.

YOUNG CC. 1964. On a new pterosaurian from Sinkiang, China. Vert Palasiat 8: 221-253.

ZHOU CF AND SCHOCH RR. 2011. New material of the non-pterodactyloid pterosaur Changchengopterus pani Lü, 2009 from the Late Jurassic Tiaojishan Formation of western Liaoning. N Jb Geol Paläont Abh 260: 265-275.

ZHOU ZH AND WANG Y. 2010. Vertebrate diversity of the Jehol Biota as compared with other lagerstätten. Sci China Earth Sci 53: 1894-1907. 